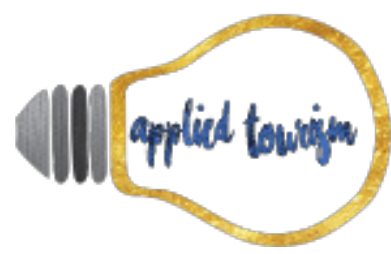

Volume 3, número 1, 2018, p. 72-92

\title{
TURISMO SUSTENTÁVEL NA COMUNIDADE CHÃ DE JARDIM EM AREIA/PB
}

\author{
Francisco Coelho Mendes \\ Doutor em Tecnologia e Inovação \\ Universidade Federal da Paraíba - UFPB \\ coelhomendesufpb2015@gmail.com \\ Priscilla Helen Medeiros Detmering \\ Bacharel em Turismo \\ Universidade Federal da Paraíba - UFPB \\ priii.86detmering@gmail.com
}

Recebido: 28 de junho, 2017

Aprovado: 29 de setembro, 2017

\section{RESUMO}

Visando minimizar os impactos socioambientais, socioculturais e econômicos, surgiu o turismo sustentável. Portanto, este estudo tem por objetivo caracterizar como a Associação para o Desenvolvimento Sustentável da Comunidade de Chã de Jardim (ADESCO), em Areia na Paraíba, desenvolve o turismo, e quais as ações e os incentivos que a associação mantém para perpetuar a prática da sustentabilidade na comunidade. A metodologia adotada é do tipo pesquisa qualitativa e descritiva, de caráter exploratório, com base no levantamento bibliográfico, consulta documental e pesquisa de campo (visita técnica e entrevista). Os resultados mostram que a ADESCO, através de ações, estratégias e projetos, ajuda desenvolver o turismo criativo, responsável e sustentável, pensando-se no bem-estar das pessoas, no bem receber o turista, e na sustentabilidade do meio ambiente e dos recursos naturais.

Palavras-chaves: Turismo Sustentável. Responsabilidade Socioambiental. Comunidade Chã de Jardim. 


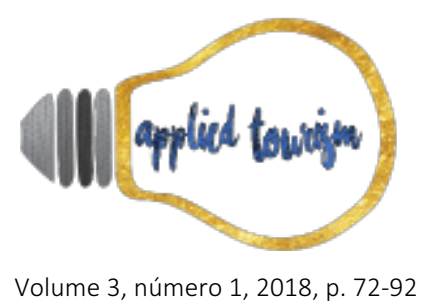

\section{INTRODUÇÃO}

O turismo é conhecido como sendo atividades realizadas por pessoas em viagens para lugares diferentes do seu lugar de moradia. Por outro lado, sabe-se que o turismo é um processo complexo que inclui vários fatores motivacionais na decisão de escolha do turista sobre o destino a ser visitado. O turismo também é uma atividade que produz impactos, sejam eles positivos, negativos ou ambos os impactos, tanto para a sociedade quanto para o meio ambiente onde suas atividades são desenvolvidas.

Visando minimizar os impactos negativos, surge o conceito de turismo sustentável, que tem como objetivo o não esgotamento dos recursos naturais e culturais, e minimizar a agressão ao meio ambiente, por meio de ações, projetos e estratégias de desenvolvimento turístico.

Dessa forma, a Associação para o Desenvolvimento Sustentável da Comunidade de Chã de Jardim (ADESCO), em Areia na Paraíba, surgiu da ideia de associar empreendimentos e projetos para, através do desenvolvimento sustentável do turismo, beneficiar as pessoas que residem na Comunidade Chã de Jardim, bem como utilizar os recursos naturais da região com o intuito de criar produtos sustentáveis de qualidade, considerando a proteção ao meio ambiente. Por isso, encontrou no turismo sustentável um meio de desenvolver os seus projetos para que haja o mínimo de impacto possível.

Diante do exposto, questiona-se: como a Associação para o Desenvolvimento Sustentável da Comunidade de Chã de Jardim (ADESCO), em Areia-Paraíba, desenvolve o turismo sustentável, e quais são os projetos, ações e incentivos que a associação, junto com os colaboradores da comunidade, mantém para perpetuar a prática da sustentabilidade na comunidade?

Este estudo tem por objetivo geral, caracterizar como a ADESCO desenvolve as práticas de turismo sustentável e responsabilidade socioambiental na comunidade Chã de Jardim. Para isso, foram desenvolvidos os seguintes objetivos específicos: identificar os incentivos e 


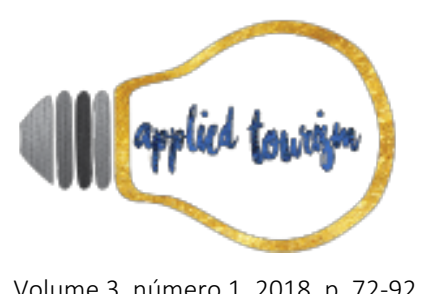

apoios que são mantidos entre a ADESCO e as lideranças locais, para que os colaboradores/trabalhadores da comunidade continuem desenvolvendo o turismo de forma sustentável; e identificar quais as ações e estratégias de responsabilidade socioambiental utilizadas no que se refere ao desenvolvimento sustentável do turismo na comunidade.

Tal estudo, justifica-se pelo nosso interesse sobre o desenvolvimento sustentável do turismo no Brejo Paraibano, devido a importância que o turismo tem como agente transformador das comunidades envolvidas. Outra motivação, surgiu com algumas inquietações com relação ao desenvolvimento da gestão corresponsável, ações e estratégias aplicadas pelos gestores da Comunidade Chã de Jardim, visando o desenvolvimento turístico da região.

\section{DESENVOLVIMENTO SUSTENTÁVEL DO TURISMO}

O termo "desenvolvimento sustentável" surgiu em 1984, por ocasião da Comissão Mundial sobre Meio Ambiente e Desenvolvimento, criada pela Organização das Nações Unidas (ONU) e presidida pela Gro Harlem Brudtland, então primeira-ministra da Noruega. A comissão propôs que houvesse a integração entre desenvolvimento econômico e a questão ambiental (ONU, 1991), e tinha como objetivos principais propor novas formas de cooperação entre os países para reexaminar e tratar os problemas e questões relacionadas ao meio ambiente e ao desenvolvimento para elevar o nível de compreensão e comprometimento por parte dos indivíduos e organizações (MTur, 2007).

Em 1987, com a conclusão dos trabalhos, a comissão elaborou o documento, "Nosso Futuro Comum ou Relatório Brundtland", que apresentava críticas ao sistema de desenvolvimento vigente na época, apresentando um diagnóstico dos problemas globais ambientais e defendia que, para que haja o desenvolvimento sustentável, é necessário que este seja viável economicamente, suportável ecologicamente e equitativo do ponto de vista social e da ética (Dias, 2003 apud MTur 2016). 


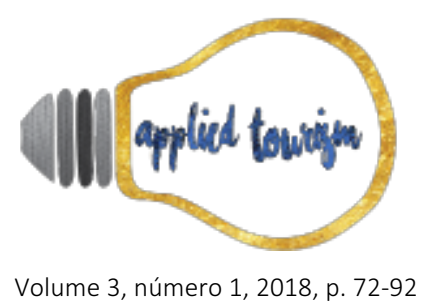

Em 1992, foi realizada, na cidade do Rio de Janeiro, a II Conferência Mundial sobre Meio Ambiente e Desenvolvimento, promovida pela ONU. A ECO-92 (ou Rio-92), como é mais conhecida, tinha como objetivo debater os problemas ambientais mundiais e alertava sobre a esgotabilidade de vários recursos naturais, o que levou a vários questionamentos sobre os modelos de desenvolvimento da época. Nessa conferência também foram assinados a Agenda 21 e vários outros documentos e tratados sobre a biodiversidade, as florestas, o clima, a desertificação e o uso e acesso dos recursos naturais de todo o planeta (Dias, 2003).

Montibeller-Filho (2001, p.281) ressalta que, "diferentes apropriações do conceito de desenvolvimento sustentável são feitas na sociedade, por diversos grupos de interesse, cada qual considerando apenas a dimensão para si mais conveniente. "

Para Veiga (2006), o desenvolvimento sustentável baseia-se no tripé desenvolvimento econômico, ambiental e social.

O desenvolvimento sustentável seria então aquele que "atende às necessidades do presente sem comprometer as possibilidades das gerações futuras atenderem suas próprias necessidades" (Pnuma, 1988, p.9). O que significa dizer, que há desenvolvimento sustentável quando utilizamos os recursos naturais, levando-se em conta o respeito às pessoas e a dignidade humana e preservando o meio ambiente, ou seja, conciliando o desenvolvimento econômico, sociocultural e ambiental. Ou seja, o desenvolvimento sustentável surgiu como uma alternativa na busca pelo desenvolvimento, e também pelo equilíbrio e pela harmonia entre a sociedade, a economia e o meio ambiente.

Em se tratando de turismo, a Organização Mundial de Turismo (OMT, 2001), conceitua o turismo como as atividades realizadas por pessoas em viagens para lugares diferentes do seu lugar de moradia e que ocorre no período menor que um ano, com finalidade de lazer, negócios entre outras. Já Beni (2006), define turismo como um processo complexo que inclui vários fatores motivacionais na decisão de escolha do potencial turístico que se refere ao destino a ser visitado. 


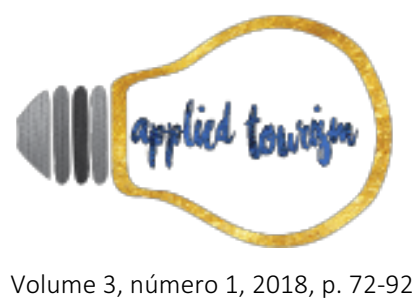

Conforme Ferreira (2008), o turismo é uma atividade que afeta de forma direta a sociedade onde está inserido, produzindo então mudanças sócio espaciais, pois facilita a interação de diferentes grupos sociais. A maneira como é planejado, organizado e operado produz impactos positivos e/ou negativos à sociedade e ao meio ambiente das comunidades locais.

Nesse processo, um aspecto do turismo que está em ascensão é o turismo sustentável, que tem apresentado um crescimento considerável nos últimos anos. Isso significa o aumento da demanda de turistas que buscam uma atividade que os proporcione um contato maior com a natureza. Mas, para que a atividade seja de fato sustentável é necessário que ocorra a conservação e/ou proteção do meio ambiente através de ações e estratégias de desenvolvimento turístico.

Conforme Butler (1998), antes da década de 1970 os envolvidos com o desenvolvimento do turismo não se importavam com o meio ambiente ou as questões sociais, buscavam apenas obter lucro, não se preocupando com as consequências e/ou impactos causados pela atividade turística. A ideia de desenvolvimento sustentável foi oficialmente incorporada ao turismo numa conferência realizada pela OMT, na década de 1990, a Conferência Mundial de Turismo Sustentável (CMTS).

Foi defendido na Conferência que o turismo sustentável está conectado ao desenvolvimento econômico e que esse modelo de turismo foi criado para que haja melhora da qualidade de vida das pessoas da comunidade receptora, para que se ofereça qualidade de experiências para o turista e para que a qualidade do ambiente seja mantida (OMT, 1996).

Segundo Coriolano \& Lima (2003), o desenvolvimento é um conceito complicado, que foge das nossas vidas e realidades. Ele nos remete à economia, mas sabemos que as atividades econômicas é que devem estar a serviço do desenvolvimento. Pois, desenvolvimento diverge de crescimento econômico.

Evidenciou-se que o crescimento econômico é apenas uma faceta do desenvolvimento, e não um fim em si mesmo. Embora seja necessário, esse 


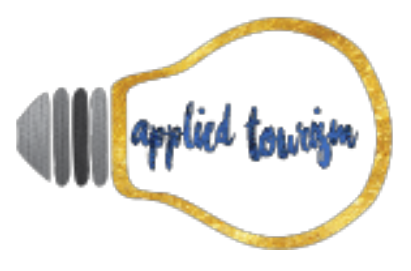

Volume 3, número 1, 2018, p. 72-92

crescimento não é garantia de qualidade de vida nem deve ser encarado sempre como positivo, uma vez que pode produzir graves consequências ambientais, como o esgotamento dos recursos naturais e a poluição (MTur, 2007, p.17).

O MTur (2007) define turismo sustentável como a atividade que mantém os aspectos culturais, a diversidade biológica e a integridade dos ambientes naturais para o futuro, ao mesmo tempo em que satisfaz as necessidades dos visitantes e das regiões receptoras no presente. Portanto, o turismo sustentável ocorre quando existe uma harmonia entre a atividade turística, a natureza e a comunidade anfitriã, com a finalidade de se conservar os recursos naturais para as gerações futuras.

O desenvolvimento sustentável e o desenvolvimento do turismo estão ligados à preservação do meio ambiente, visto que a sustentabilidade é uma estratégia que busca um equilibrado desenvolvimento dos destinos turísticos (Matheus,Morais \& Caffagni, 2005).

Segundo Swarbrooke (2000, p.19), a sustentabilidade do turismo é definida como "formas de turismo que satisfaçam hoje as necessidades dos turistas, da indústria do turismo e das comunidades locais, sem comprometer a capacidade das futuras gerações de satisfazerem suas próprias necessidades".

O turismo é uma atividade que tanto pode vir a induzir como depender do desenvolvimento sustentável. E a sustentabilidade do turismo pode ser entendida de maneira abrangente, mas sempre tendo como foco a preservação dos recursos naturais, da cultura e da comunidade receptora. É necessário que o trade turístico adote práticas sustentáveis para que se reduzam os custos e se minimizem os impactos socioambientais de seus empreendimentos (MTur, 2016).

Para o MTur (2016), as práticas e as ações sustentáveis adotadas pelos empreendimentos turísticos podem reduzir o consumo de energia e de água, orientar a maneira correta de descartar os resíduos, valorizar a cultura local, incentivar as pessoas e os prestadores de serviços turísticos a se tornarem agentes e multiplicadores do turismo sustentável, beneficiando o destino, o meio ambiente e a comunidade local. 


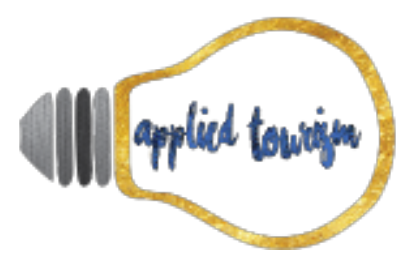

Volume 3, número 1, 2018, p. 72-92

\begin{abstract}
O estudo do turismo deve ser direcionado para o desenvolvimento sustentável, conceito essencial para alcançar metas de desenvolvimento sem esgotar os recursos naturais e culturais nem deteriorar o meio ambiente. Entende-se que a proteção do meio ambiente e o êxito do desenvolvimento turístico são inseparáveis. (Ansarah, 2001, p.30).
\end{abstract}

O ritmo acelerado das mudanças econômicas e socioambientais tem provocado os empreendedores e os consumidores com relação à sustentabilidade. Dallas (2009) explica que os empreendimentos que incorporam a sustentabilidade e que atuam na gestão dos impactos causados pelas suas atividades, produtos e serviços, adquirem maior visibilidade no mercado e retorno financeiro positivo.

Para Sachs (1993), o planejamento do desenvolvimento sustentável precisa considerar, simultaneamente, cinco aspectos de sustentabilidade:

a) Social, como sendo a criação de um processo de desenvolvimento sustentado na equidade da distribuição de renda e de bens, de modo a reduzir o abismo entre os padrões de vida dos ricos e dos pobres;

b) Econômico, através da alocação e do gerenciamento mais eficiente dos recursos e de um fluxo constante de investimentos públicos e privados;

c) Ecológico, por meio da prática da melhoria contínua, a partir do uso de ferramentas, como: Intensificar o uso de recursos dos diversos ecossistemas, com o mínimo de danos aos sistemas de sustentação da vida; Limitar o consumo de combustíveis fósseis e produtos que são facilmente esgotáveis ou danosos ao meio ambiente, substituindo-os por recursos ou produtos renováveis e/ou abundantes; Reduzir o volume de resíduos e de poluição, através da conservação de energia e de recursos e da reciclagem; Promover a autolimitação no consumo de materiais por parte dos países ricos e dos indivíduos em todo o planeta; Intensificar a pesquisa para a obtenção de tecnologias de baixo teor de resíduos e eficientes no uso de recursos para o desenvolvimento urbano, rural e industrial.

d) Espacial, planejado com o intuito de obter uma configuração rural-urbana mais equilibrada e uma melhor distribuição territorial, com ênfase em: Reduzir da concentração massiva nas metrópoles; Frear a destruição de ecossistemas frágeis; Promover o 


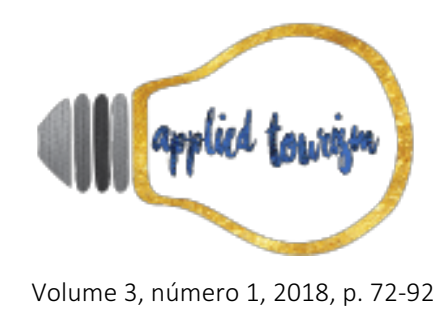

desenvolvimento da agricultura; Explorar o potencial da industrialização descentralizada; Criar uma rede de reservas naturais e de biosfera, para proteger a biodiversidade.

e) Cultural, dar-se-á pela procura de raízes endógenas de processos de modernização e de sistemas agrícolas integrados, em um conjunto de soluções específicas para o local, o ecossistema, a cultura e a área.

Segundo Sachs (2000), a prática da sustentabilidade deve ter uma visão holística dos problemas da sociedade, e não focar apenas na gestão dos recursos naturais. É a busca por algo mais amplo, que visa uma verdadeira metamorfose do modelo de civilização atual.

Quanto a sustentabilidade do turismo, o MTur (2007) expõe quatro aspectos:

a) Ambiental, o meio ambiente é a base dos recursos tanto naturais quanto culturais da atividade turística, que é dependente da qualidade e da proteção do meio ambiente.

b) Sociocultural, associado aos princípios de uma sociedade humanizada, ou seja, existem possibilidades das pessoas, através de uma distribuição equitativa de renda e de bens, viverem uma vida digna, com qualidade de vida, com direito ao trabalho, a educação, a liberdade e a participação na construção da sua comunidade, em uma sociedade sustentável, que não busca apenas acumular lucros com o que produz, diminuindo assim os níveis de exclusão social.

c) Econômico, associado a eficiência da economia, à competitividade e à lucratividade. Busca o desenvolvimento econômico considerando os aspectos ambientais e sociais, e não somente na obtenção de lucro e de produção em grande escala a qualquer custo, sem pensar nos impactos negativos causados pelo crescimento econômico.

d) Político-institucional, refere-se a solidez e continuidade das parcerias e dos compromissos estabelecidos entre os diversos agentes e agências governamentais dos três níveis de governo e nas três esferas de poder, além daqueles atores situados no âmbito da sociedade civil.

É a visão holística e a metamorfose da civilização que nos proporciona essa evolução e a melhoria contínua do entendimento sobre desenvolvimento sustentável ou sustentabilidade. 


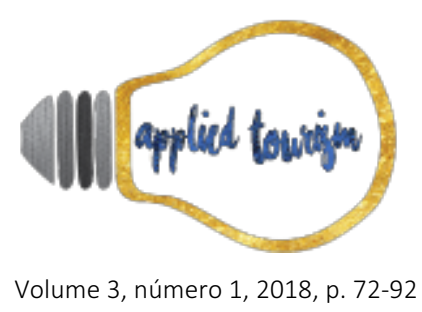

\section{METODOLOGIA}

Conforme Gil (2007), a pesquisa é um processo formal e sistemático de desenvolvimento do método científico. Esses métodos de pesquisa são utilizados para se obter conhecimento sobre uma determinada realidade ou fenômeno, e que tem por objetivo responder os problemas através do emprego de processos científicos, para a promoção de determinado conhecimento.

A metodologia adotada é do tipo pesquisa qualitativa e descritiva, de caráter exploratório, com base no levantamento bibliográfico, consulta documental e pesquisa de campo (visita técnica, observação direta e entrevista).

O universo desta pesquisa é composto por comunidades que desenvolvem o turismo de base comunitária. A amostra é composta por colaboradores e moradores da Comunidade Chã de Jardim, que desenvolvem atividades do turismo sustentável.

A coleta de dados foi obtida no período de julho a novembro de 2016, por meio de visita técnica (observação direta) junto aos colaboradores e moradores da Comunidade Chã de Jardim (Restaurante Rural Vó Maria, fábrica de polpas de frutas Doce Jardim, trilha ecológica da Mata do Pau Ferro, palheiras do Arte na Mão e ADESCO); bem como, entrevista com Luciana Balbino de Souza, atual presidente da ADESCO, e com Rejane Ribeiro, cantora do Pôr-do-sol de Maria e colaboradora da comunidade.

A análise dos dados foi feita por meio da técnica de análise de conteúdo, que ocorre através da interpretação e da comparação das informações recebidas. O estudo em questão, limitase a descrever as ações e as estratégias da Comunidade Chã de Jardim quanto a aplicação do turismo sustentável, sob a perspectiva do turismo de base comunitária. 


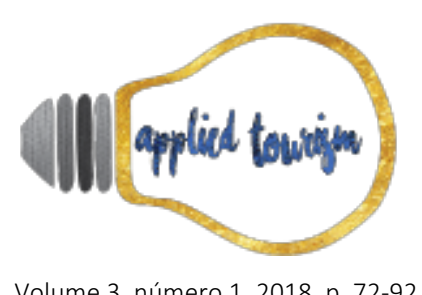

\section{ESTUDO DE CASO: COMUNIDADE CHÃ DE JARDIM EM AREIA/PB}

Os segmentos do turismo que são praticados no município de Areia na Paraíba, são o turismo de aventura, religioso, negócios, ecoturismo, histórico-cultural, turismo sustentável, entre outros.

A Comunidade Chã de Jardim está localizada no município de Areia-PB, mais precisamente a 7 km do centro da cidade, próximo à divisa dos municípios de Areia e Remígio na Paraíba.

A Associação para o Desenvolvimento da Comunidade de Chã de Jardim (ADESCO), gerida por Luciana Balbino de Souza, é uma associação privada e que foi fundada em 2006 por um grupo formado por 20 jovens do município de Areia. Tem como principal atividade as associações para a defesa dos direitos sociais dos moradores da Comunidade Chã de Jardim (Econodata, 2016). Esses jovens da comunidade viram na natureza uma oportunidade de negócio e de independência financeira, mediante a exploração do turismo sustentável.

Conforme Balbino (2016), os projetos realizados pela ADESCO têm o turismo como principal atividade, pois a associação desenvolve vários atrativos para que os turistas visitem a Comunidade Chã de Jardim. E, como consequência, a comunidade é conhecida por desenvolver o turismo sustentável, e vem se tornando referência para os empreendedores do turismo no Brasil. Aproximadamente 30 pessoas da comunidade atuam diretamente nos projetos desenvolvidos pela associação, colaborando para o desenvolvimento da comunidade, o que gera renda e emprego para cerca de 200 famílias.

Corroborando com esse tipo de desenvolvimento, os autores Coriolano \& Lima (2003, p.69) afirmam:

Queremos o turismo de dimensão local, capaz de mobilizar e de permitir que os habitantes se façam participantes de um projeto, e consigam trabalhar juntos. [...] O desenvolvimento local é um processo dinamizador da sociedade local, que se realiza mediante o aproveitamento eficiente dos recursos endógenos existentes na comunidade $[. .$.$] .$ 


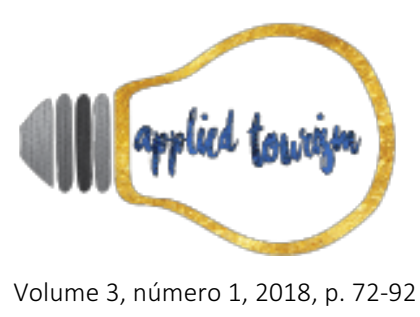

Segundo Balbino (2016), a história do desenvolvimento da comunidade começou em 2006, com a reativação da fábrica de polpa de frutas orgânicas (sem agrotóxicos e sem fertilizantes), que produz a polpa de frutas "Doce Jardim". Ela também explica que, posteriormente, surgiram outros projetos e empreendimentos como, por exemplo:

- O "Arte na Mão" - projeto de artesanato feito com a palha seca de bananeira e produzido por mulheres da comunidade;

- O "Restaurante Rural Vó Maria" - empreendimento que serve comida caseira com pratos típicos da culinária regional;

- O "Piquenique na Mata" - um lanche servido também com comidas típicas e oferecido aos turistas que optam por fazer a caminhada guiada na trilha no Parque da Mata do Pau Ferro;

- O "Pôr-do-Sol de Maria" - projeto desenvolvido na comunidade desde 2013. É um evento agendado, onde a jovem cantora Rejane Ribeiro, canta a música Ave Maria ao pôr-do-sol, no Restaurante Rural Vó Maria.

Tais projetos e empreendimentos desenvolvidos pela ADESCO na Comunidade Chã de Jardim têm o apoio institucional e/ou incentivo de lideranças locais como:

- Prefeitura Municipal de Areia-PB (Fórum do Brejo Paraibano);

- Centro de Ciências Agrárias da Universidade Federal da Paraíba (Areia$\mathrm{PB})$;

- Empresa de Assistência Técnica e Extensão Rural (EMATER);

- Serviço Nacional de Apoio à Micro e Pequenas Empresas (SEBRAE) Paraíba;

- Serviço Nacional de Aprendizagem Rural (SENAR);

- Banco do Nordeste (Fountain of Encouragement);

- Ministério da Agricultura, Pecuária e Abastecimento (MAPA); 


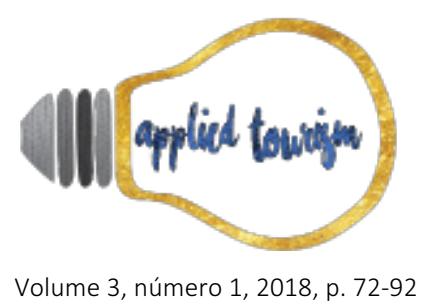

- Secretaria de Turismo e Desenvolvimento Econômico do Estado da Paraíba.

Como reconhecimento de que a Comunidade Chã de Jardim é um produto turístico consolidado, que oferece produtos e serviços de qualidade, sempre prezando pela sustentabilidade e pelo desenvolvimento socioambiental da comunidade, a ADESCO, em 2014, foi premiada com duas importantes premiações na área do turismo. A presidente da associação, Luciana Balbino de Souza, no $3^{\circ}$ Prêmio BRAZTOA de Sustentabilidade em Maceió-AL, foi premiada em $2^{\circ}$ lugar. A $3^{\circ}$ edição do prêmio dado pela Associação Brasileira das Operadoras de Turismo (BRAZTOA), contou, pela primeira vez, com o apoio do Ministério do Turismo, o que fortalece a credibilidade da premiação (UFPB, 2014).

Outra premiação dada à Luciana Balbino de Souza foi o Troféu Waldemar Duarte, da Associação Brasileira de Jornalistas do Turismo na Paraíba (ABRAJET-PB), que busca valorizar as iniciativas na área do turismo (Balbino, 2016).

Recentemente, o restaurante foi premiado pela Agência Nacional de Cultura, Empreendedorismo e Comunicação (ANCEC), com o Selo Referência \& Qualidade Empresarial, prêmio referência nacional de gastronomia, em Junho de 2016 (Ancec, 2016)

\section{DESCRIÇÃO DOS RESULTADOS}

Nesta fase da pesquisa, descreveremos os empreendimentos e projetos desenvolvidos pela ADESCO na Comunidade Chã de Jardim em Areia na Paraíba.

\section{Restaurante Rural Vó Maria}

O Restaurante Rural Vó Maria, que pertence à ADESCO, foi fundado em junho de 2013 e está localizado na rodovia PB-79, na Comunidade Chã de Jardim, Areia-PB. É conhecido pela preparação de comida caseira típica da região do Nordeste brasileiro. E tem esse nome 


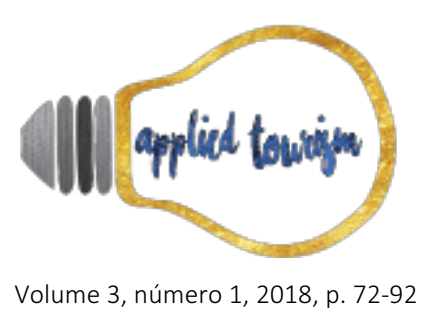

como uma homenagem à comida caseira preparada pela avó da Luciana Balbino de Souza, que se chama Maria (Balbino, 2016).

Conforme Balbino (2016), diariamente, os turistas que visitam o local desfrutam da comida regional, que é preparada no fogo a lenha e com produtos orgânicos (sem adição de agrotóxicos e sem fertilizantes), produzidos na própria comunidade.

Segundo Balbino (2016), uma das peculiaridades do restaurante é o fato de o turista, além de almoçar a comida caseira e típica nordestina, pelo valor único de $\mathrm{R} \$ 15,00$ reais, pode ter a experiência de ele mesmo colher as folhas da horta orgânica que é cultivada no restaurante, para a preparação da sua própria salada. ..."A comida é preparada por pessoas da comunidade, e o cardápio também é elaborado por elas. Os produtos utilizados também são cultivados pela comunidade local, como os legumes, as hortaliças e as galinhas, todos são produtos orgânicos".

Esse tipo de prática, enquadra-se na definição de um segmento do turismo, conhecido como turismo de experiência. O turismo de experiência é definido como uma nova maneira de consumir o turismo, onde o importante é valorizar as peculiaridades de cada destino, onde o turista busca por experiências diferenciadas e a personalização da viagem (Sebrae, 2016).

Conforme informações do inventário turístico desenvolvido em 2015 por alunos da Universidade Federal da Paraíba (UFPB), através do Programa de Extensão do curso de graduação em Turismo, o Paraíba Criativa, "diariamente o Restaurante Rural Vó Maria recebe turistas e parceiros, a exemplo da empresa Guia Mundo Turismo Receptivo, que sempre leva grupos para conhecer os produtos lá comercializados" (Paraíba Criativa, 2015). E de fato, foi constatado, através das visitas técnicas a comunidade, que o fluxo de turistas e grupo de turistas ou visitantes é intenso no local, principalmente nos finais de semana. 


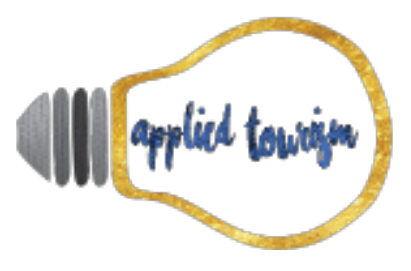

Volume 3, número 1, 2018, p. 72-92

Segundo Balbino (2016), a decoração do restaurante, ela é rústica e feita pelas artesãs do projeto Arte na Mão. "Além de decorar o ambiente, essa é uma maneira que encontramos para divulgar o trabalho das artesãs, que usam a palha seca de bananeira para confeccionar os seus produtos".

Outro aspecto observado, foi a preocupação da gestão do restaurante com a acessibilidade ao local, fazendo com que o espaço seja acessível para as pessoas com deficiência ou com mobilidade reduzida.

Corroborando com essa afirmativa, o MTur (2009, p.28) expõe que:

Certamente, a garantia de satisfação no atendimento será um diferencial significativo para um amplo mercado consumidor, o de viajantes com deficiência ou mobilidade reduzida, naquelas localidades que estejam acessíveis às suas necessidades, desde agências e receptivos de viagem, aeroportos e empresas aéreas, hotéis, atrativos, bares, restaurantes e similares.

\section{Projeto Pôr-do-Sol de Maria}

É um projeto associado ao turismo, idealizado pela ADESCO, em 2013 e acontece no Restaurante Rural Vó Maria, o projeto Pôr-do-Sol de Maria. Tal projeto é um produto turístico que tem o objetivo de incentivar as atividades culturais, como a música.

Conforme Lage \& Milone (2001, p.51) expõem:

Produto turístico é o conjunto de bens e serviços relacionados a toda e qualquer atividade de turismo. Especificamente, o produto turístico pode ser definido como um produto composto, equivalente a um amálgama formado pelos seguintes componentes: transporte, alimentação, acomodação e entretenimento.

Conforme o Jornal O Globo (2013), com o apoio do Sebrae, a cantora Rejane Ribeiro é contratada para se apresentar nos restaurantes e hotéis de Areia. O projeto serviu de incentivo para que a jovem lançasse o seu CD na Feira do Empreendedor, realizada anualmente pelo Sebrae. A cantora também se apresenta em outro projeto da ADESCO, o Piquenique na Mata. 


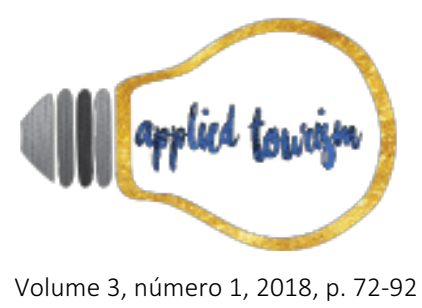

Conforme Ribeiro (2016), cantora do projeto, "os turistas podem ouvir música popular brasileira enquanto desfrutam de um lanche com comidas típicas, preparado pelo restaurante". Ela também afirma que começou cantando em uma igreja da cidade de Areia, e que cantar no projeto é algo muito especial e satisfatório.

Segundo Ribeiro (2016), o "Pôr-do-Sol de Maria" é um evento que ocorre aos sábados, podendo também ser agendado, que acontece no final da tarde, no restaurante. Nele, uma jovem cantora da comunidade, Rejane Ribeiro, canta a música "Ave Maria”. Essa é uma maneira de envolver os jovens da comunidade nos projetos desenvolvidos pela ADESCO.

\section{Projeto Doce Jardim}

Segundo Balbino (2016), este é o primeiro projeto da ADESCO, que foi a reabertura da fábrica de polpa de fruta da Comunidade Chã de Jardim, em 2006. A unidade de produção de polpa de frutas Maria do Carmo da Costa Libório (DADÁ) estava fechada desde 1996, e só voltou a funcionar graças ao grupo de jovens da ADESCO, que decidiram reabrir a fábrica com nome "Doce Jardim" para produzir polpa de fruta e criar uma fonte de renda para os agricultores familiares da comunidade, que fornecem as frutas à fábrica. A implementação do projeto contou com o apoio de instituições como a Empresa Técnica de Assistência e Extensão (EMATER) - Governo do Estado da Paraíba; o Serviço Nacional de Aprendizagem Rural (SENAR), e o Serviço Brasileiro de Apoio às Micro e Pequenas Empresas (SEBRAE).

Conforme o Jornal O Globo (2013), na fábrica de polpa de frutas trabalham cinco jovens. Por dia, são feitos $230 \mathrm{~kg}$ de polpa de frutas, tudo certificado pelo Ministério da Agricultura. São vendidos sacos de $1 \mathrm{~kg}$, contendo 10 pacotes de 100 gramas. Cada pacote de $1 \mathrm{~kg}$ custa $\mathrm{R} \$ 5$ reais, e cada pacote pode produzir até cinco litros de suco.

Segundo Ribeiro (2016) as poupas de frutas são vendidas para os turistas que visitam o Restaurante Rural Vó Maria. São comercializadas também em estabelecimentos das cidades da região, como Alagoa Grande, Areia, Remígio, Juarez Távora, entre outras. Incluindo as 


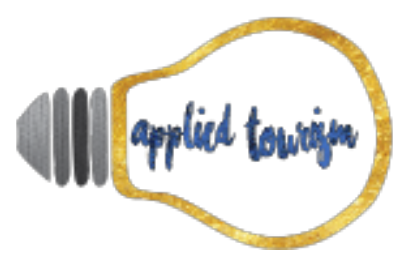

Volume 3, número 1, 2018, p. 72-92

escolas, que usam os sucos feitos com as poupas "Doce Jardim" em suas merendas escolares.

Conforme Balbino (2016), o projeto "Doce Jardim" conta com o apoio conjunto da Prefeitura Municipal de Areia-PB com a Universidade Federal da Paraíba (UFPB). Neste projeto, são produzidos diferentes sabores de suco, como abacaxi, manga, goiaba, umbucajá, acerola, cajá e caju, frutas tropicais, típicas da região. Ressalta também, que o grande diferencial no processo de fabricação das poupas de frutas, é que "são todas produzidas ou colhidas pelos agricultores familiares da região, são frutas orgânicas (sem agrotóxicos), e a polpa é feita sem água, sem conservantes e sem produtos químicos".

Veiga et al. (2006) afirma que a aplicação de agrotóxicos pode contaminar os alimentos, o solo e os sistemas hídricos, o que resulta na degradação do meio ambiente, o prejuízo à saúde dos animais e das pessoas, e alterações consideráveis nos ecossistemas.

Como a administração e o manejo da propriedade estão a cargo do proprietário, se ele for orientado e apoiado pela política de governo de forma correta, os sistemas agroecológicos terão grande êxito, aumentando a geração de empregos, a fixação do homem no campo, e promovendo a melhoria da renda dos pequenos produtores, aumento do número de propriedades com diversificação de cultivos, entre outros benefícios. (MMA, 2016, p.51).

Para Ribeiro (2016), as pessoas que trabalham diretamente na fabricação da polpa de frutas, e os agricultores familiares da comunidade, contam com as instruções e orientações da EMATER. A entidade orienta essas pessoas tanto a não usarem agrotóxicos na produção das frutas quanto a fazerem o replantio de mudas frutíferas.

\section{Projeto Arte na Mão}

Segundo Ribeiro (2016), o projeto "Arte na Mão", fundado em 2013, é mais uma das iniciativas da ADESCO. Onde um grupo de artesãs produzem artesanato com a palha seca da folha de bananeira, que é abundante na região do brejo paraibano. Essas artesãs fabricam desde bolsas a esteiras, utilizando a palha seca da bananeira. 


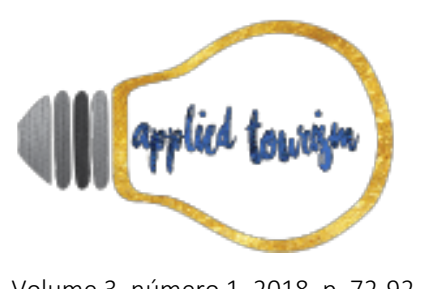

Observamos que, a arte de transformar as palhas secas em produtos para serem vendidos aos turistas ajuda no orçamento doméstico e no estudo dos filhos.

Segundo Balbino (2016), as mulheres da comunidade, que estão inseridas no projeto, podem contar com uma renda extra, além da renda do projeto social do governo, o Bolsa Família.

\begin{abstract}
Para o turismo ser sustentável no sentido social e no cultural, ele deve ser desejado pelos habitantes locais e deve ser percebido como benéfico para a maioria da população local, não apenas para a elite. Ele deve proporcionar empregos para os qualificados assim como para os sem qualificação e gerar oportunidades para avanços sociais e econômicos (Swarbrooke, 2000, p.128).
\end{abstract}

Balbino (2016) explica que com o apoio do Sebrae, os produtos feitos pelas artesãs foram melhorados para atender ao público-alvo, que são turistas que visitam o Restaurante Rural Vó Maria. "O Sebrae foi o apoio crucial para que os produtos se tornassem mais refinados e assim pudessem ser comercializados". No Restaurante Rural Vó Maria, "os turistas são convidados a tecer a palha da bananeira, e podem levar para casa essas peças que eles mesmos produziram".

\title{
Projeto Piquenique na Mata
}

Conforme Balbino (2016), a ideia do projeto "Piquenique na Mata", fundado em 2013, é oferecer aos turistas passeios guiados que começam em uma trilha ecológica na reserva ecológica Parque Estadual Mata do Pau-Ferro, um dos últimos remanescentes de Mata Atlântica do Nordeste. E uma das preocupações da ADESCO é desenvolver o turismo sustentável, preservando o meio ambiente e as culturas locais.

Segundo Silva (2002), a Mata Atlântica é importante para o equilíbrio original dos ecossistemas, a conservação da biodiversidade faunística e a regulação de fluxos dos recursos hídricos, possibilitando o controle do clima e a estabilidade de escarpas e encostas.

Através do projeto, os turistas podem fazer trilhas ecológicas, e ao final das trilhas podem desfrutar de um piquenique preparado pelo Restaurante Rural Vó Maria. Os turistas podem 


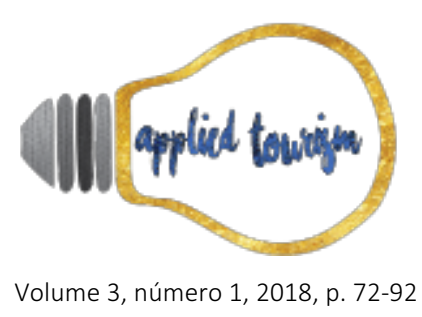

também plantar uma muda de árvore pau-ferro, contribuindo para a manutenção da reserva e incentivando o espírito de conservação nas pessoas (Paraíba Criativa, 2015).

Balbino (2016) afirma que as comidas e os sucos são preparados no restaurante e levados até o local do piquenique. "Colocamos a comida nas esteiras feitas de palha pelas artesãs, e os turistas, ao final de cada trilha, podem apreciar a paisagem enquanto se deliciam com o lanche". Todo esse processo é conduzido por um guia de turismo, devidamente habilitado ao exercício da função.

Observa-se que esses projetos possuem ações e estratégias que são planejadas e aperfeiçoadas pela ADESCO, mediante o incentivo de lideranças locais para o desenvolvimento sustentável do turismo junto à comunidade.

\section{CONSIDERAÇÕES FINAIS}

O presente estudo buscou evidenciar a importância da sustentabilidade no processo de desenvolvimento do turismo na Comunidade Chã de Jardim, Areia/PB. Pode-se perceber, que neste caso o desenvolvimento sustentável não é apenas um conceito, mas uma conduta. São práticas, individuais ou coletivas, que beneficiam tanto a comunidade quanto o meio ambiente. Essas práticas buscam o desenvolvimento sustentável, sejam através de apoio a projetos sociais e políticas para a redução de resíduos, sejam através da reutilização de recursos naturais.

A ADESCO surgiu da ideia de associar a fábrica de polpa de frutas, o artesanato local feito com a palha seca de bananeira, as oficinas de artesanato, as trilhas ecológicas realizadas no Parque Estadual Mata do Pau Ferro, o piquenique na mata, e o Restaurante Rural Vó Maria, para definir, através de estratégias e ações, os projetos lá implementados e vivenciados. Tudo isso, com o intuito de desenvolver o turismo sustentável, defendendo os direitos sociais dos moradores da Comunidade Chã de Jardim, utilizando os recursos naturais de maneira sustentável, preocupando-se com o meio ambiente, propiciando renda às famílias 


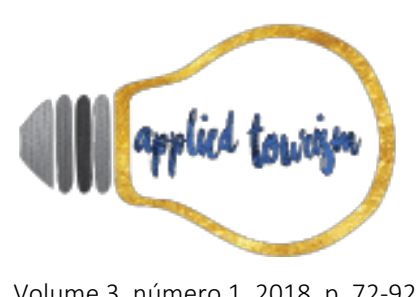

da comunidade, e oferecendo conhecimento, produtos e serviços de qualidade aos turistas que visitam a comunidade.

Portanto, Azevedo \& Rigon (2010) expõem que o desenvolvimento sustentável resgata as premissas de equidade social; da distribuição de riquezas; do fim da exploração dos seres humanos; da eliminação das discriminações de gênero, raça, geração ou qualquer outra; da garantia de direitos a vida, felicidade, saúde, educação, moradia, cultura, emprego e envelhecimento com dignidade; da democracia plena, além da responsabilidade ecológica e da participação cidadã como partes indissociáveis do desenvolvimento.

Dessa forma, surgiu a ADESCO, da união de ideias de jovens, que tinham a preocupação tanto de mudar a realidade das pessoas da comunidade através do cuidado com o meu ambiente, quanto da busca em mostrar, através de projetos de turismo sustentável, a sua cultura, simplicidade e criatividade. Por isso, a Comunidade Chã de Jardim é um exemplo de que é possível desenvolver o turismo de maneira sustentável e criativa, pensando-se no bem-estar das pessoas, no bem receber o turista, e na sustentabilidade do meio ambiente e dos recursos naturais.

\section{REFERÊNCIAS}

Ancec (2016). Agência Nacional de Cultura, Empreendedorismo e Comunicação. Sobre Nós. Ancec. Disponível em: www.ancec.net.br/sobre-nos. Acesso em 31 out. 2016.

Ansarah, M. G. R. (2001). Turismo: como aprender, como ensinar. (Org.). São Paulo: Senac.

Azevedo, E. \& Rigon, S. A. (2010). Sistema alimentar com base na sustentabilidade. In: Taddei, J. A. A. C. et al. (Org.). Nutrição em saúde pública. Rio de Janeiro: Rubio.

Balbino, L. S. (2016). Presidente da Associação para o Desenvolvimento Sustentável da Comunidade de Chã de Jardim (ADESCO). Entrevista em 15 out. 2016. Areia-PB.

Beni, M. C. (2006). Política e planejamento de turismo no Brasil. São Paulo: Aleph.

Butler, R. (1998). Sustainable tourism: looking backwards in order to progress? In: Hall, M. \& Lew, A. (Org.). Sustainable tourism: a geographycal analysis. Essex, UK: Addison Wesley Longman Limited. 


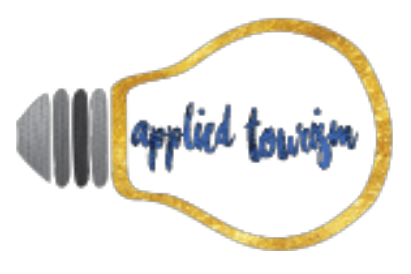

Volume 3, número 1, 2018, p. 72-92

Coriolano, L. N. \& Lima, L. C. (2003). Turismo e desenvolvimento social sustentável. Fortaleza: EDUECE.

Dallas, N. (2009). Como tornar sua empresa ecologicamente responsável. Green Business Basics.

Dias, R. (2003). Turismo sustentável e meio ambiente. São Paulo: Atlas.

Econodata. (2016). Associação para o Desenvolvimento Sustentável do Turismo - ADESCO. Disponível em: www.econodata.com.br/lista_empresas/paraiba/areia/a/07618830000126associacao-para-o-desenvolvimento-sustentavel-da-comunidade-da-cha-do-jardim-adesco. Acesso em 01 nov. 2016.

Ferreira, H. C. H. (2008). Turismo e responsabilidade social: um debate no campo da sustentabilidade. UFRRJ, CPDA. Disponível em: www.proppi.uff.br. Acesso em 15 set. 2016.

Gil, A. C. (2007). Métodos e técnicas de pesquisa social. 5 ed. São Paulo: Atlas.

Jornal O Globo. (2013). Projetos em Areia na Paraíba incentivam o empreendedorismo. Reportagem de Jorge Machado. Disponível em: http://g1.globo.com/pb/paraiba/noticia/2013/01/projetos-em-areia-na-paraibaincentivam-o-empreendedorismo.html. Acesso em 20 Jul. 2016.

Lage, B. H. G. \& Milone, P. C. (2001). Economia do turismo. 7. ed. São Paulo: Atlas.

Matheus, C. E.; Morais, A \& Caffagni, C. (2005). Educação ambiental para o turismo sustentável. São Carlos: RIMA.

MMA (2016). Ministério do Meio Ambiente. Alimentos: os impactos da produção. Plano de Ação para a Produção e Consumo Sustentáveis. Brasília: MMA. Disponível em: www.mma.gov.br/estruturas/secex_consumo/_arquivos/4\%20-\%20mcs_alimentos.pdf. Acesso em: 12 nov. 2016.

Montibeller-Filho, G. (2001). O mito do desenvolvimento sustentável: meio ambiente e custos sociais no moderno sistema produtor de mercadorias. Florianópolis: UFSC.

MTur (2016). Ministério do Turismo. Introdução a uma viagem de inclusão. Turismo e Sustentabilidade. v.1. Brasília: MTur. Disponível em: www.turismoacessivel.gov.br/ta/downloads/adaptar/NOLUME_IIntroducao_a_uma_Viag em_de_Inclusao.pdf Acesso em 12 nov. 2016.

MTur (2009). Ministério do Turismo. Orientações para prestadores de serviços turísticos. Turismo e Sustentabilidade. Brasília: MTur.

MTur (2007). Ministério do Turismo. Programa de regionalização do turismo: roteiros do Brasil. Turismo e Sustentabilidade. Brasília: MTur.

ONU (1991). Organização das Nações Unidas. Comissão Mundial sobre Meio Ambiente e Desenvolvimento. Nosso futuro comum. Tradução de: "Our Common Future". Rio de Janeiro: ONU. 


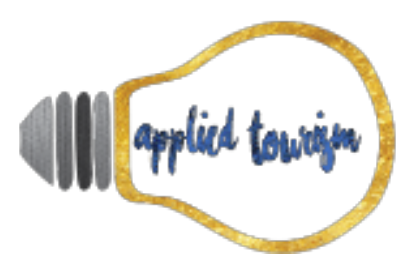

Volume 3, número 1, 2018, p. 72-92

Paraíba Criativa. (2015). Restaurante Rural Vó Maria. Areia, Paraíba. Disponível em: www.paraibacriativa.com.br/artista/restaurante-rural-vo-maria. Acesso em 20 jul. 2016.

Pnuma (1988). Programa das Nações Unidas sobre Meio Ambiente. Bruxelas, 1987. Nosso futuro comum. Tradução de: "Our Common Future". Rio de Janeiro: FGV.

Ribeiro, R. (2016). Colaboradora da Associação para o Desenvolvimento Sustentável da Comunidade de Chã de Jardim (ADESCO). Entrevista em 15 out. 2016. Areia-PB.

Sachs, I. (1993). Estratégias de transição para o século XXI. In: Bursztyn, M. Para pensar o desenvolvimento sustentável. São Paulo: Brasiliense.

SACHS, I. (2000). Caminhos para o desenvolvimento sustentável. Coleção Ideias Sustentáveis. In: Stroh, P. Y. (Org.). Rio de Janeiro: Garamond.

Sebrae (2016). Serviço Nacional de Apoio às Micro e Pequenas Empresas. Tendências para turismo de experiência. DEBRAE. Disponível em: www.sebrae.com.br/sites/PortalSebrae/ufs/ms/artigos/tendencias-para-turismo-deexperiencia,8a39f05fbbe23510VgnVCM1000004c00210aRCRD. Acesso em 12 nov. 2016.

Silva, M. C. (2002). Geoprocessamento aplicado à análise ambiental na reserva ecológica estadual da Mata do Pau Ferro, Areia-PB. Monografia (Graduação em Geografia). Centro de Educação, Universidade Estadual da Paraíba. Campina Grande: UEPB.

Swarbrooke, J. (2000). Turismo sustentável: conceitos e impacto ambiental. São Paulo: Aleph.

UFPB (2014). Universidade Federal da Paraíba. Centro de Ciências Agrárias. Comunidade Chã do Jardim é finalista de prêmio nacional de turismo sustentável. Areia, Paraíba: CCA-UFPB. Disponível em: https://ccaufpb.wordpress.com/2014/12/01/comunidade-da-cha-dojardim-e-finalista-de-premio-nacional-de-turismo-sustentavel. Acesso em 11 nov. 2016.

Veiga, J. E. (2006). Meio ambiente \& desenvolvimento. São Paulo: SENAC.

Veiga, M. M.; Silva, D. M.; Veiga, L. B. E.; Faria, M. V. C. (2006). Análise da contaminação dos sistemas hídricos por agrotóxicos numa pequena comunidade rural do Sudeste do Brasil. Caderno de Saúde Pública. v.22, nº.11. Rio de Janeiro, Nov/2006. p. 2391-2399. 